Supplement of Nat. Hazards Earth Syst. Sci., 19, 313-323, 2019

https://doi.org/10.5194/nhess-19-313-2019-supplement

(C) Author(s) 2019. This work is distributed under

the Creative Commons Attribution 4.0 License.

(c) (1)

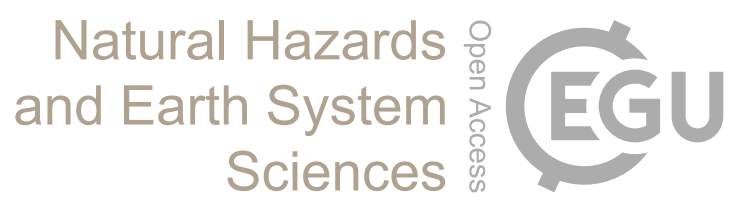

Supplement of

\title{
Communicating disaster risk? An evaluation of the availability and quality of flood maps
}

Daniel Henstra et al.

Correspondence to: Daniel Henstra (dhenstra@uwaterloo.ca)

The copyright of individual parts of the supplement might differ from the CC BY 4.0 License. 


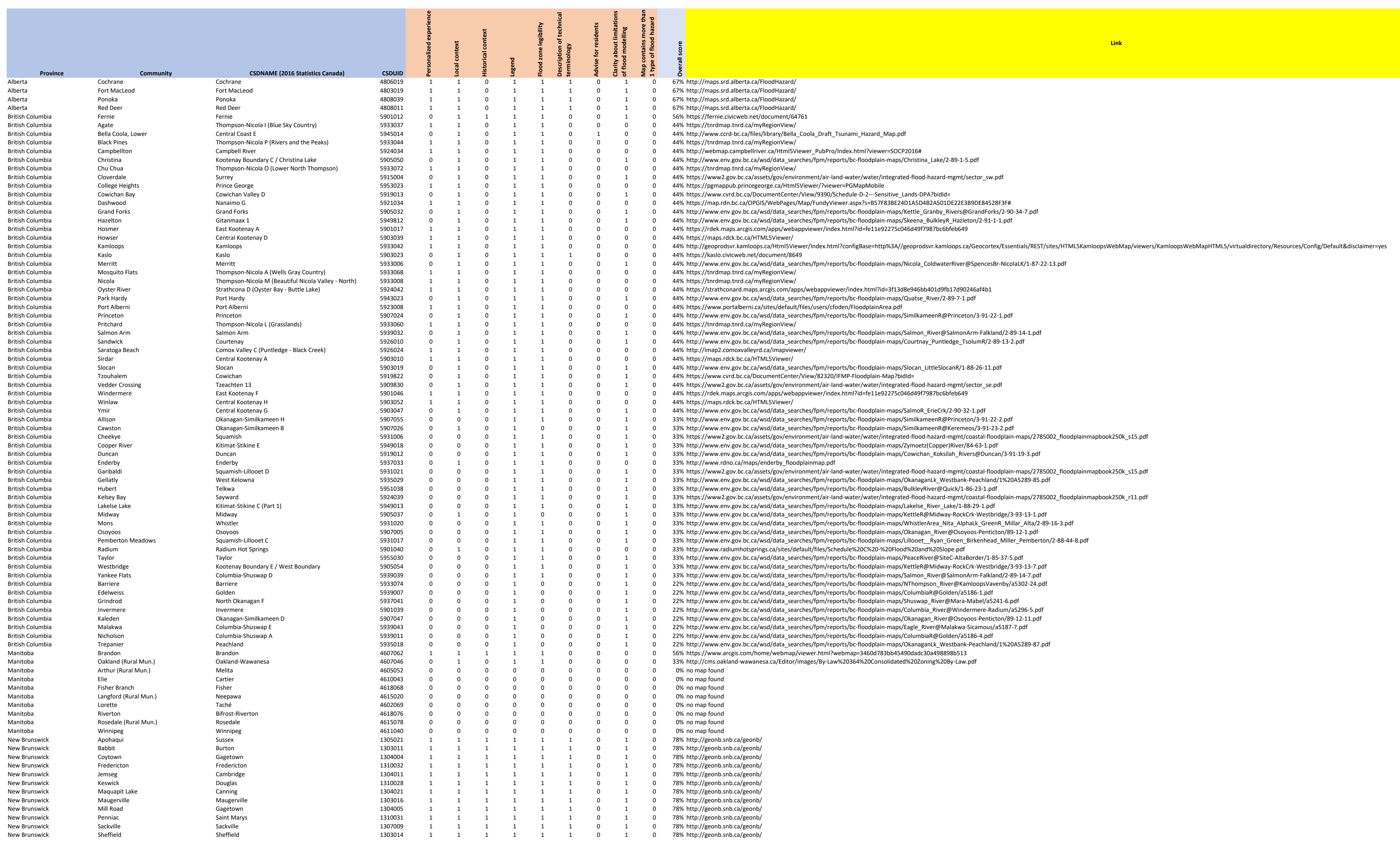




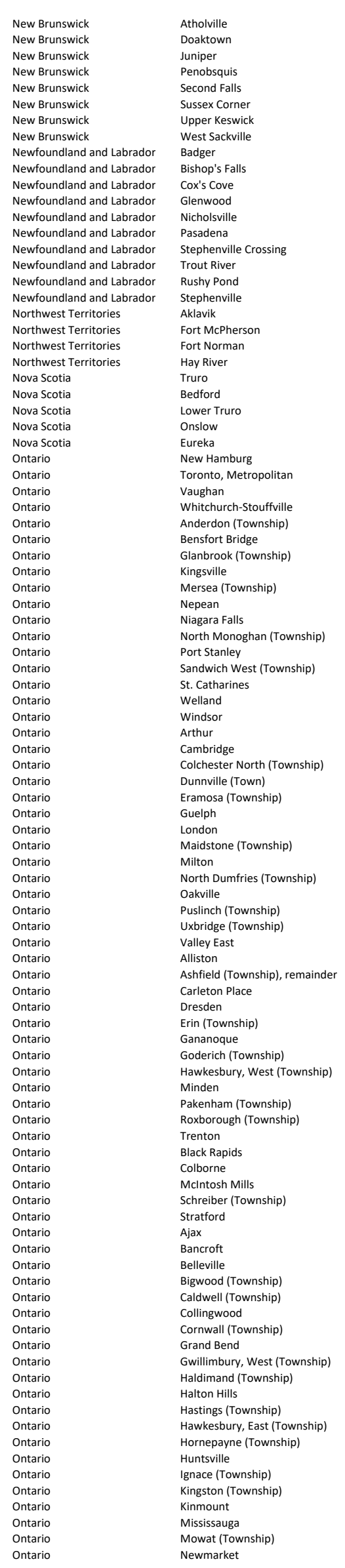

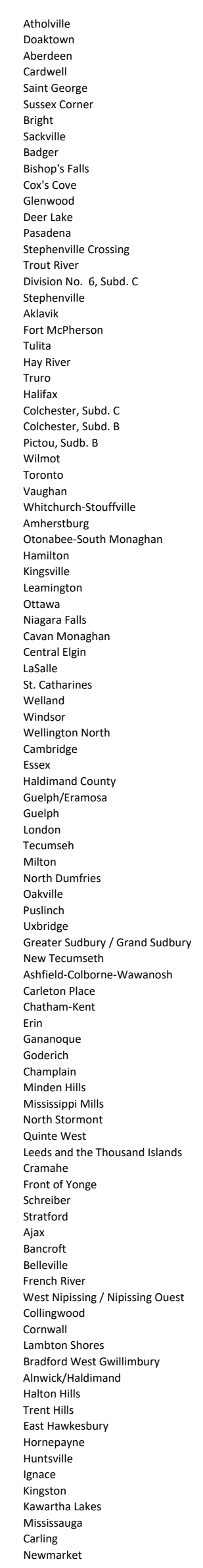



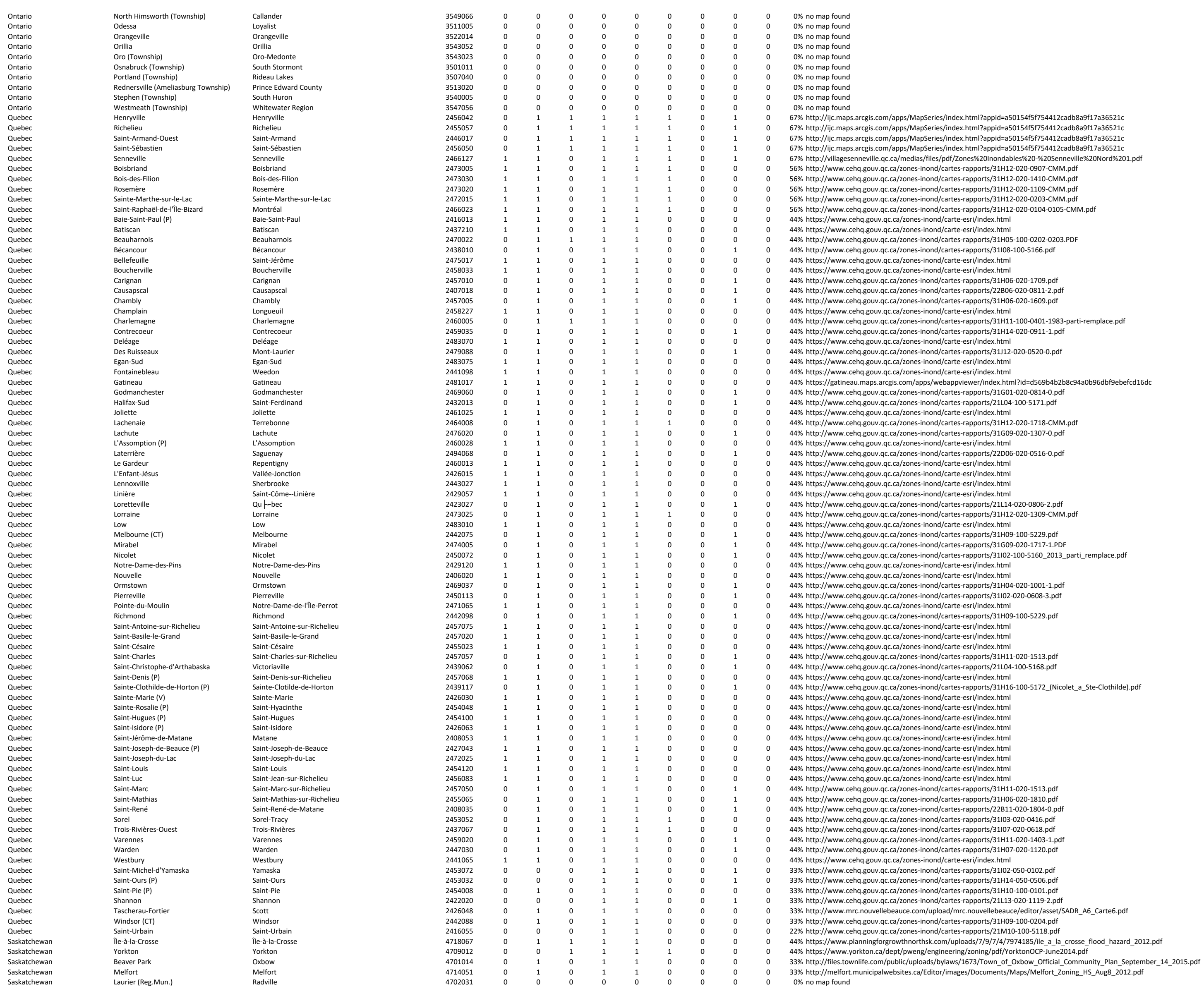